\title{
Optimum Calcium Concentration of Dialysis Fluid for Maintenance Haemodialysis
}

\author{
A. J. WING,* M.A., B.M., B.CH., M.R.C.P.
}

\begin{abstract}
Cummary : To define the minimum and maximum levels $\checkmark$ for calcium concentration of dialysis fluid a combination of acute and long-term observations was carried out.
\end{abstract}

In acute experiments the external calcium balance during dialysis was dependent on the gradient between plasma ultrafilterable calcium and dialysis fluid calcium concentration. Changes in plasma calcium during dialysis did not correlate with measured external balance.

In long-term studies it was found that raising the dialysis fluid calcium concentration from 5.0 to $6.0 \mathrm{mg}$./ $100 \mathrm{ml}$. both arrested biochemical and radiological changes of hyperparathyroidism, and, by causing a progressive fall in plasma phosphates, made metastatic calcification less likely. Raising the concentration to $6.5 \mathrm{mg} . / 100 \mathrm{ml}$. in an attempt to compensate for negative alimentary calcium balance caused nausea and vomiting in some patients.

A concentration of $6.0 \pm 0.2 \mathrm{mg} . / 100 \mathrm{ml}$. is recommended.

\section{Introduction}

Estimations of the calcium balance during haemodialysis based on measurements of the arteriovenous difference across the dialyser have been reported by Ogden and Holmes (1966), Kaye et al. (1966), and Verberckmoes (1966). Direct measurements of the external calcium balance during haemodialysis have not been previously reported. The long-term effects of different dialysis fluid calcium concentrations have been compared at wide differences only, and the optimum concentration remains to be defined (Shaldon, 1966 ; Sokol et al., 1967). Recently reported concentrations vary between $2.5 \mathrm{mg}$./100 ml. (Freeman et al., 1965) and $10 \mathrm{mg} . / 100 \mathrm{ml}$. (Patel et al., 1967).

The question is one of great practical importance, since a large proportion of patients dialysed for long periods have developed evidence of metabolic bone disease, and in many of them this has caused significant morbidity (Curtis et al., 1966 ; Schreiner et al., 1966).

This paper reports results of short-term and long-term studies carried out in order to define the optimum dialysis fluid calcium concentration.

\section{Methods}

\section{Net Transfer of Calcium}

An individual single pass dialysis system was assembled for the purpose of studying the calcium balance during the dialysis of a single patient. The dialysis fluid was prepared as an individual batch and mixed in a single 500-litre plastic tank; 400 litres of dialysis fluid were prepared for each of these

\footnotetext{
* Lately, Senior Medical Registrar, Department of Medicine, Charing Cross Hospital Medical School, Fulham Hospital, London W.6. A present : Nuffield Fellow in the Department of Medicine, Makerere University College, P.O. Box 7072, Kampala, Uganda.
}

studies. After its single passage through the Kiil dialyser the dialysate was collected in a single reservoir of 365 litres. capacity. Only the fluid which had flowed through the dialyser after the beginning of the patient's dialysis was collected in this manner. The fluid which flowed through the dialyser for 15 minutes before dialysis in order both to warm the dialyser and to ensure the isotonicity and homogeneity of its priming. fluids was discarded. All dialyses were carried out with a dialysis fluid flow rate of about $500 \mathrm{ml}$. per min. The adequacy of the mixing of the water and concentrated salt solution in the batch tank was checked either by measurement of the sodium content of the dialysis fluid or by determination. of its electrical conductivity.

An aliquot of the batch tank fluid was taken for the estimation of initial calcium concentration (Ca-i). When the dialysis. was completed, including the saline wash-back, the dialysate collected in the reservoir was mixed and an aliquot taken for the estimation of final calcium concentration (Ca-f). Because the object of the experiments was to compare the calcium concentration of the initial (Ca-i) and final fluids (Ca-f), these estimations were carried out on duplicate samples in pairs.

In order to increase the magnitude of the difference, $\mathrm{Ca}-\mathrm{i}$ minus $\mathrm{Ca}-\mathrm{f}$, the calcium content of the initial fluid (Ca-i) was varied over a wide range. By this means a greater exchange of calcium either from the dialysis fluid to the patient-dialyser complex or in the reverse direction was achieved. Total transfer of calcium was calculated from the difference $\mathrm{Ca}-\mathrm{i}$ minus Ca-f corrected for the measured total volume of dialysate used.

Twelve experiments were performed. In three of these the initial calcium level was low $(2.95-4.05 \mathrm{mg} . / 100 \mathrm{ml}$.) ; in three it was high $(7.5-8.05 \mathrm{mg} . / 100 \mathrm{ml}$.) ; and in the remainder it was in the range $4.75-6.3 \mathrm{mg} . / 100 \mathrm{ml}$. None of the patients received blood transfusions during the dialyses, which were of 12 hours' duration.

Total plasma calcium was measured on a blood sample taken immediately before dialysis from the arterial cannula (pl Ca-pre) and on a similar sample taken after dialysis (pl Ca-post) Calcium determinations were made on a flame photometer (Eppendorf).

\section{Calcium on Dialysis Membranes}

In these experiments the calcium content of a single Kiil dialyser was determined in a standard manner. The four membranes and any fluids present in the dialyser were placed in Vitreosil beakers, in which they were evaporated to dryness under infrared lights. The beakers were then placed in a muffle furnace for three hours at $300^{\circ} \mathrm{C}$. followed by 12 hours. at $600^{\circ} \mathrm{C}$. to complete the ashing. The ashings were then eluted with dilute hydrochloric acid $(2-3 \%)$ and the calcium content was estimated by flame photometry (Eppendorf).

Two control experiments were carried out with dry membranes and two further control experiments without membranes to determine if any calcium was present in the flasks, glassware, or reagents used. 
Three experiments were carried out to determine the total calcium adsorbed on to the membranes and contained in the dialyser at the beginning of dialysis. The Kiil dialyser was prepared according to standard techniques, and placed in the dialysis circuit as for dialysis. At the moment at which the patient would have been connected for dialysis the dialyser was disconnected from the dialysis fluid supply. The calcium content of the dialyser was then determined as described above. In the same manner three experiments were carried out to determine the total calcium on the membranes and within the dialyser at the completion of a standard haemodialysis.

\section{Alimentary Calcium Balances}

One formal balance study has been carried out with the patient in hospital, the methods described by Clarkson et al. (1966) being used. Unfortunately the patient was partially immobilized during some of this study because of problems concerning the arteriovenous shunt.

Two outpatients have been studied, chromium sesquioxide being used as a continuous faecal marker (Clarkson et al., 1966). Dietary intake was estimated from detailed dietary histories recorded by the patients in pocket notebooks. The calcium content of each water supply relevant to the assessment of intake was estimated.

\section{Estimation of Ultrafilterable Calcium}

Ultrafilterable calcium was determined on ultrafiltrates prepared by centrifugation in a Toribara flask (Toribara et al., 1957). Samples from control subjects were venous and were obtained without any venous occlusion. Samples from dialysis patients were obtained from the arterial cannula immediately before dialysis. All samples were withdrawn anaerobically into heparinized syringes. The syringe was capped and the blood was centrifuged in the syringe with the nozzle uppermost. To make this possible the plunger was held in position with struts made from a Perspex cylinder split longitudinally, the two semi-cylinders being reunited about the plunger and held together with rubber bands. The plasma was transferred to Visking tubing through a disposable needle bent to about 75 degrees around its container. Transfer was carried out within a plastic bag filled with gas $\left(5 \% \mathrm{CO}_{2}\right.$ and $\left.95 \% \mathrm{O}_{2}\right)$. When the Visking had been positioned in the flask (Nordin and Smith, 1965) the flask was flushed through with humidified gas for 30 seconds (Prasad and Flink, 1958). Again, all manœuvres were carried out within the "synthetic alveolar" environment of the plastic bag. All estimations were made in duplicate on ultrafiltrates prepared separately from the same sample of plasma. If the results did not agree to $0.1 \mathrm{mg}$./ $100 \mathrm{ml}$., then that estimation was discarded.

Calcium was determined by a flame photometer.

\section{Long-term Effect of Changes in Dialysis Fluid Calcium Concentration}

Until November 1966 the dialysis fluid was prepared by mixing tap water and either distilled or deionized water so that the desired final calcium concentration was achieved. The proportions were gauged by filling the tanks up to a marked level with processed water before adding the tap water. London tap water has a fairly constant calcium content, and the full range over three years in the mains water supply used has been 9.2-10.7 mg./100 ml. Nevertheless, some seasonal changes in the hardness do occur and periodic adjustments in the markings on the tanks were necessary in order to maintain the desired final calcium concentration. At its best, and starting with the advantage of the constancy of the hardness of London tap water, it was not possible to achieve the desired levels more closely than $\pm 0.5 \mathrm{mg}$. $/ 100 \mathrm{ml}$. on any one occasion. After November 1966 all the water used for dialysis was softened in a commercial base exchange water softener and calcium was added as calcium chloride to the concentrate. Once the producers of the concentrated salt solution had solved some initial problems in quality control it became possible to set the dialysis fluid calcium concentration to more precise limits $( \pm 0.2 \mathrm{mg}$./ $100 \mathrm{ml}$.).

The estimated mean values of calcium concentration used from June 1965 to December 1967 are shown in the upper part of Fig. 3. Until the end of March 1966 the intended concentration was $5 \mathrm{mg} . / 100 \mathrm{ml}$. However, owing to seasonal changes and delay in making the necessary adjustments the concentration was lower than intended during the last five months of 1965 and higher than intended during the early part of 1966. In April 1966 the calcium concentration was raised to $5.5 \mathrm{mg}$. $/ 100 \mathrm{ml}$. for a short time and subsequently to $6 \mathrm{mg} . / 100 \mathrm{ml}$. The fall to $5.5 \mathrm{mg} . / 100 \mathrm{ml}$. during the autumn of 1966 is accounted for by a change in the concentration of calcium in the mains supply from $10.5-10.7 \mathrm{mg} . / 100 \mathrm{ml}$. in May-July to $9.6-9.8 \mathrm{mg} . / 100 \mathrm{ml}$. in August-October. During the summer and autumn of 1967 concentrations of 6.5 and $6.2 \mathrm{mg} . / 100 \mathrm{ml}$. have been used.

Throughout the sequence of changes described above, plasma calcium, phosphate, and alkaline phosphatase were determined in all patients on monthly samples of blood taken from the arterial cannula immediately before dialysis. The same estimations were repeated on a similar sample taken at the end of the same dialysis. On these samples calcium was estimated by the method of Trinder (1960), phosphate by Technicon AutoAnalyzer, and alkaline phosphatase by the method of Kind and King (1954). The results of slit-lamp examinations of the cornea and of skeletal $x$-ray examinations will be given elsewhere (Curtis et al., 1968).

\section{Results}

\section{Net Calcium Transfer to and from Dialysis Fluid}

The results for all 12 experiments are shown in Table I. The differences in calcium concentration ( $\mathrm{Ca}-\mathrm{i}$ minus $\mathrm{Ca}-\mathrm{f}$ ) were in some of the experiments of a similar order to the error of the determination itself. There were, nevertheless, clear and distinct differences, upheld by repeated determinations on duplicate pairs of samples. Because of the large volume of dialysate used and the small difference in calcium concentration from which the net balance was calculated, each balance was subject to an estimated experimental error of $\pm 100 \mathrm{mg}$. of calcium. Ultrafiltration of the patient's plasma is indicated by the weight loss during the dialysis. Blood flows varied with cannula function, and were between 100 and $250 \mathrm{ml} . / \mathrm{min}$.

The results have shown that net calcium transfer during dialysis is dependent on the gradient between plasma calcium concentration and dialysis fluid calcium concentration. Calcium balance has been varied in both a positive and a negative direction by changes in the dialysis fluid concentration.

These experiments have shown that the difference between the plasma calcium before and after dialysis did not correlate with the observed external net calcium transfer. A fall in the plasma concentration of the order of $0.5 \mathrm{mg}$. $/ 100 \mathrm{ml}$. occurred with net transfer of from +187 to $-1.114 \mathrm{mg}$. of calcium. In five experiments the change in dialysis fluid calcium content indicated that an infusion of calcium had occurred during the dialysis. In four of these the plasma calcium after dialysis rose, but in one it fell. Four patients were in negative calcium balance during the dialysis; one of these had a small rise in plasma calcium at the end of dialysis. The difficulty in estimating calcium transfer from a consideration of changes in plasma calcium was especially apparent in those patients in whom the net transfer was small. 
TABI.E I.-Dialysis Calcium Balances

\begin{tabular}{|c|c|c|c|c|c|c|c|c|c|c|}
\hline \multirow{3}{*}{$\begin{array}{l}\text { Expt. } \\
\text { No. }\end{array}$} & \multirow{3}{*}{$\begin{array}{c}\text { Weight } \\
\text { Change } \\
\text { (kg.) }\end{array}$} & \multirow{3}{*}{$\begin{array}{l}\text { Blood } \\
\text { Flows } \\
\pm 50 \mathrm{ml} .\end{array}$} & \multicolumn{6}{|c|}{$\mathrm{Ca} / \mathrm{mg} . / 100 \mathrm{ml})}$. & \multirow{3}{*}{$\begin{array}{c}\text { Vol. } \\
\text { Dialysate } \\
\text { (Litres) }\end{array}$} & \multirow{3}{*}{$\begin{array}{c}\text { Net } \\
\text { Calcium } \\
\text { Balance } \\
\text { (mg.) }\end{array}$} \\
\hline & & & \multicolumn{3}{|c|}{ Plasma } & \multicolumn{3}{|c|}{ Dialysate } & & \\
\hline & & & Pl Ca-pre & Pl Ca-post & $\Delta$ & $\mathrm{Ca}-\mathrm{i}$ & $\mathrm{Ca}-\mathrm{f}$ & $\Delta$ & & \\
\hline $\begin{array}{r}1 \\
2 \\
3 \\
4 \\
5 \\
6 \\
7 \\
8 \\
9 \\
10 \\
11 \\
12\end{array}$ & $\begin{array}{l}-0.35 \\
-1.15 \\
-1.0 \\
-2.35 \\
-0.85 \\
-0.2 \\
+0.65 \\
-0.1 \\
-1.2 \\
-0.65 \\
-0.6 \\
-0.25\end{array}$ & $\begin{array}{l}200 \\
150 \\
175 \\
225 \\
150 \\
150 \\
150 \\
225 \\
125 \\
225 \\
175 \\
225\end{array}$ & $\begin{array}{c}8.3 \\
9 \cdot 55 \\
9 \cdot 65 \\
10 \cdot 6 \\
10 \cdot 05 \\
9 \cdot 7 \\
9 \cdot 7 \\
9 \cdot 65 \\
8.3 \\
10 \cdot 65 \\
10 \cdot 6 \\
10.9\end{array}$ & $\begin{array}{c}0 \cdot 05 \\
9 \cdot 2 \\
9 \cdot 8 \\
9 \cdot 25 \\
8 \cdot 6 \\
9 \cdot 15 \\
10 \cdot 6 \\
10 \cdot 0 \\
9 \cdot 95 \\
11 \cdot 1 \\
9 \cdot 9 \\
10 \cdot 7\end{array}$ & $\begin{array}{l}+0.35 \\
-0.35 \\
+0.15 \\
-1.35 \\
-1.45 \\
-0.55 \\
+0.9 \\
+0.35 \\
+1.65 \\
+0.45 \\
-0.7 \\
-0.2\end{array}$ & $\begin{array}{l}4.75 \\
5.65 \\
5.1 \\
3.3 \\
4.05 \\
2.95 \\
8.05 \\
7.85 \\
7.5 \\
6.3 \\
5.8 \\
5.8\end{array}$ & $\begin{array}{l}4 \cdot 65 \\
5 \cdot 60 \\
5 \cdot 2 \\
3.55 \\
4 \cdot 15 \\
3.25 \\
7.95 \\
7 \cdot 75 \\
7 \cdot 3 \\
6 \cdot 3 \\
5 \cdot 8 \\
5 \cdot 8\end{array}$ & $\begin{array}{l}+0.1 \\
+0.05 \\
+0.1 \\
-0.25 \\
-0.1 \\
-0.3 \\
+0.1 \\
+0.1 \\
+n \cdot 2 \\
0 \\
0 \\
0\end{array}$ & $\begin{array}{l}385 \\
374 \\
370 \\
384 \\
376 \\
371 \\
382 \\
379 \\
370 \\
365 \\
375 \\
382\end{array}$ & $\begin{array}{c}+385 \\
+187 \\
+370 \\
-960 \\
-376 \\
-1,114 \\
+382 \\
+379 \\
+740 \\
0 \\
0 \\
0\end{array}$ \\
\hline
\end{tabular}

\section{Calcium Present on Dialysis Membranes}

The results of 10 of these experiments are recorded in Table II. From these results it is apparent that when the dialyser was disconnected at the time that dialysis would have commenced there was an insignificant quantity of calcium adsorbed on to the membranes. The small amount of calcium present at this time was of the same order as that present at the end of the haemodialysis.

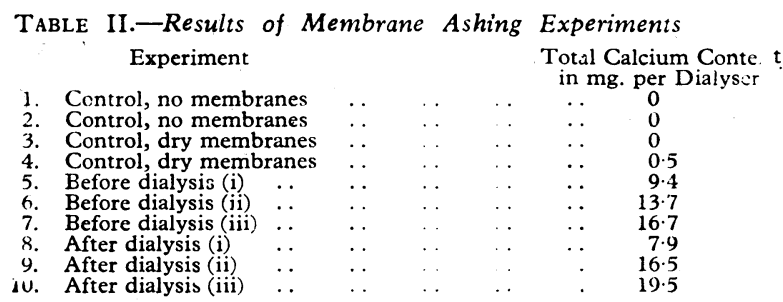

\section{Alimentary Calcium Balances}

Faecal losses of calcium are high (see Table III). Many of these patients may be in marked negative alimentary calcium balance. A negative balance of 1-7 g./week is possible. The higher losses were recorded in patients who, because of their total plasma calcium levels at the time, were probably receiving an infusion of about $0.5 \mathrm{~g}$. of calcium with each dialysis.

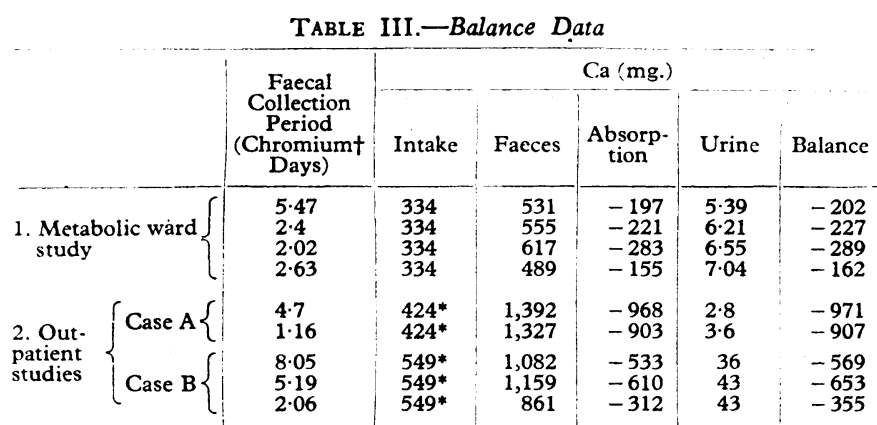

* Mean calcium intakes estimated from dietary history covering whole period of study.

$t$ Chromium days calculated from the amount of chromium recovered from the faeces in each collection period divided by the amount of chromium given each day.

\section{Ultrafilterable Calcium Levels}

The method for the estimation of ultrafilterable calcium gave good reproducibility. Estimations of calcium concentration in duplicate ultrafiltrates showed a difference no greater than the range of reproducibility for the determination of plasma calcium in duplicate samples-that is, $\pm 0.05 \mathrm{mg} . / 100 \mathrm{ml}$.in $95 \%$ of the determinations. In the remaining $5 \%$ the difference exceeded $0.5 \mathrm{mg} . / 100 \mathrm{ml}$. There was a difference in the volume of ultrafiltrate obtained in some of the samples in which the larger differences were found. The results of determinations in which the difference in calcium determinations in duplicate ultrafiltrates exceeded $0.1 \mathrm{mg} . / 100 \mathrm{ml}$. were discarded.

The results of the determinations of ultrafilterable calcium are plotted in Fig. 1. There was a wide scatter of both the total and ultrafilterable calcium in the patients. Only 20 of these results fell in the normal area as defined in 25 controls. The tendency is for the total and ultrafilterable calcium to be higher than normal in the patients, and most of the higher values are found among the estimations carried out on patients dialysed for less than a year.

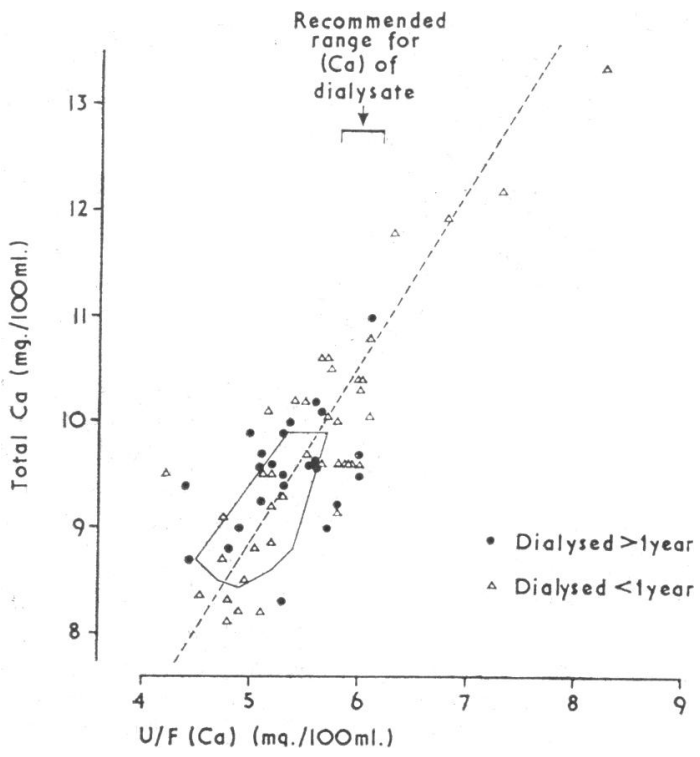

FIG. 1.-Relation between the total and ultrafilterable calcium in 64 estimations on 25 patients. The mean percentage of the rotal plasma calcium present in the ultrafiltrates was 56.7. The enclosed area was defined by 25 estimations in normal subjects.

\section{Long-term Effect of Changes in Dialysis Fluid Calcium Concentration}

Mean values of plasma calcium and phosphate before and after dialysis together with the range of all values in patients are shown in Fig. 2. It must be emphasized that changes occurring in the plasma calcium levels in different patients during dialysis have often been in opposite directions despite the fact that their dialyses were simultaneous and the gradient for diffusible calcium was similar.

When the mean dialysis fluid calcium concentration was low in November 1965 the plasma calcium levels in the patients were in the low-normal range before dialysis and fell during dialysis. At these times the plasma phosphates were higher than at the other dates shown in the figure. In November 1965 dialyses were of 12 hours' duration; in February 1966 they were increased to 14 hours. 


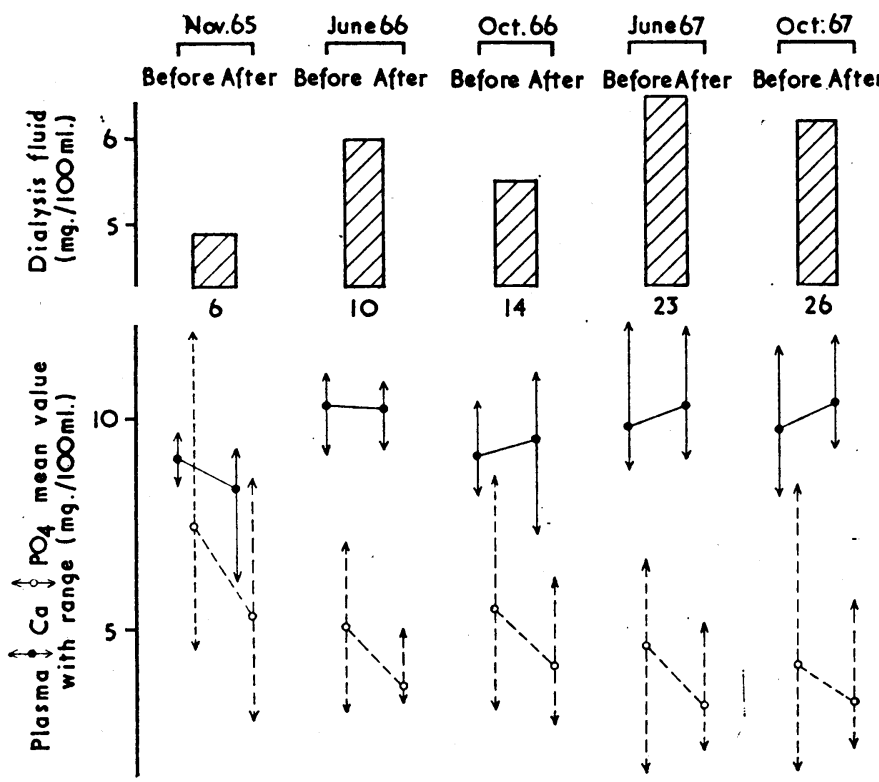

FIG. 2.-Effect of different calcium concentrations of the dialysis fluid on total plasma calcium and phosphate before and after dialysis. At the dates shown the calcium concentration had been in use for at least two months. Mean values are given together with the absolute range for all the patients being treated at the time and who had been dialysed for more than two months. The number of patients being treated at the time concerned is shown in the centre of the figure.

With a mean dialysis fluid calcium concentration of $6 \mathrm{mg}$./ $100 \mathrm{ml}$. in June 1966 the plasma calcium levels were higher before dialysis and there was little change in the mean plasma calcium levels during dialysis.

When the calcium concentration was raised to 6.5 and $6.2 \mathrm{mg} . / 100 \mathrm{ml}$. for periods during 1967 the mean plasma calcium showed a rise during dialysis. With these concentrations occasional plasma calcium levels of $12 \mathrm{mg} . / 100 \mathrm{ml}$. were reached at the end of dialysis in some patients, and a few patients experienced transient nausea and vomiting during dialysis. In the two patients in whom gastrointestinal bleeding occurred this was not provoked by hypercalcaemia. The mean lower plasma phosphate levels found at this time will be noted.

The effect of prolonged negative calcium balance during dialysis in one patient is shown in Figs. 3 and 4 . This patient
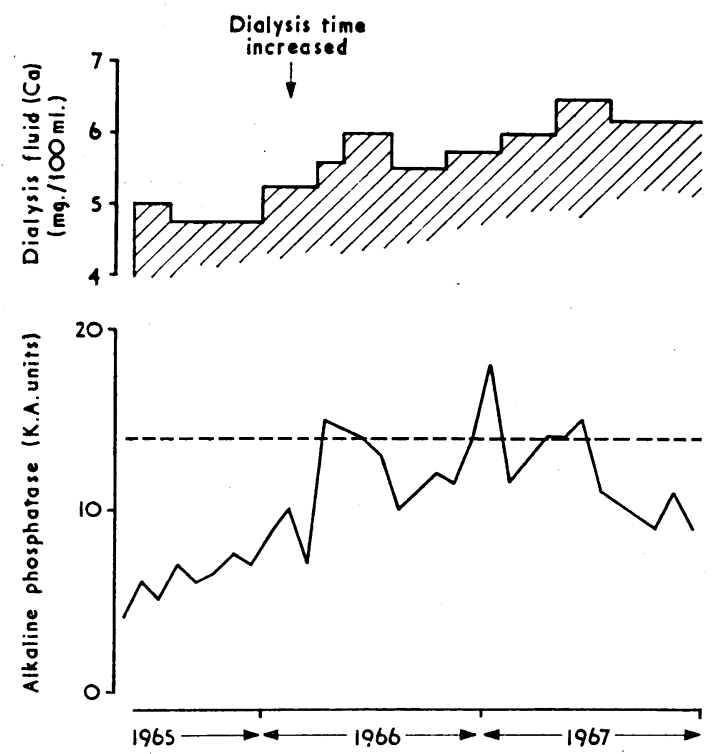

FIG. 3-The upper part indicates average dialysis fluid calcium concentration from June 1965 to December 1967. - In the lower part the results of alkaline phosphatase determinations in one patient are shown. This patient began haemodialysis in March 1964. was dialysed for almost two years with a dialysis fluid containing a calcium concentration of about $5 \mathrm{mg} . / 100 \mathrm{ml}$. There was a gradual and progressive rise in the alkaline phosphatase, and abnormal levels were reached in April 1966. At the same time minimal radiological changes of secondary hyperparathyroidism were observed (Fig. 4). After the calcium concentration of the dialysis fluid was increased the bone changes improved. The rise in the alkaline phosphatase was arrested and it remained in the normal range throughout the period July-December 1967. Vitamin D was not given to this patient.

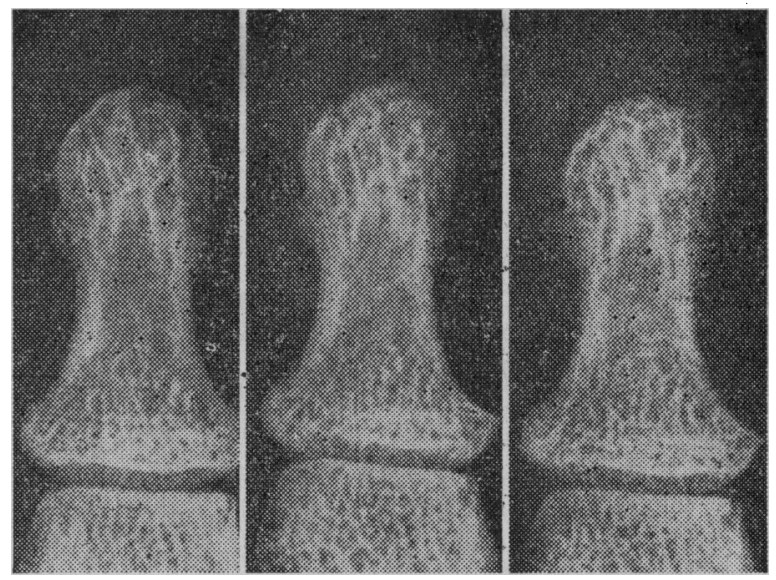

FIG. 4.-Radiological appearances of the terminal phalanx of the right middle finger in the patient whose alkaline phosthe right phatase changes are shown in Fig. 3 . The first $x$-ray film was taken, at the time of starting dialysis, the second after two years dialysis with a calcium concentration of $5 \mathrm{mg} . / 100 \mathrm{ml}$. and the third after a further 18 months' dialysis with a calcium concentration of $6 \mathrm{mg} . / 100 \mathrm{ml}$. Note the increasing resorption with subsequent healing.

\section{Discussion}

The fraction of the calcium present in the ultrafiltrates was similar to that in normal controls. This is in contrast to the findings of Kaye et al. (1967) but consistent with the normal plasma proteins and $\mathrm{pH}$ values found in our patients (Curtis et al., 1968).

The relation between the external calcium balance during dialysis and the initial gradient for ultrafilterable calcium is shown in Fig. 5. This figure can be used to predict the expected net transfer of calcium. If the gradient exceeds $1 \mathrm{mg}$. in either direction there will be a net transfer of between 250 and $500 \mathrm{mg}$. of calcium during a 12-hour dialysis. The transfer will be larger during the usual 14-hour dialysis.

The minimum level of the calcium concentration of the dialysis fluid is dictated by the necessity of avoiding a negative dialysis calcium balance. This is important because all the available evidence indicates that the gastrointestinal absorption of calcium is poor and that the patients have more calcium in their faeces than they consume in their diets, which have a low calcium content (Curtis et al., 1966 ; Kaye et al., 1967). Furthermore, the effect of lowering the plasma calcium level is to stimulate the secretion of the parathyroid hormone (Care et al., 1966). The experiments of Talmage et al. (1957) have particular relevance. These workers have carried out peritoneal dialysis in nephrectomized rats with the use of calcium-free dialysis fluid. The "low calcium stress" was shown to provoke an increase in osteoclastic activity in animals in whom the parathyroids were intact. If parathyroidectomy was performed this histological change was not observed, and the plasma calcium fell to a lower level.

The lack of correlation between plasma calcium changes and observed external calcium balance has been pointed out above. The maintenance of normal plasma calcium levels at the end of dialysis is no guarantee that negative calcium balance has not occurred during that dialysis; rather it may simply be a measure of the effectiveness of the response of the parathyroids. 


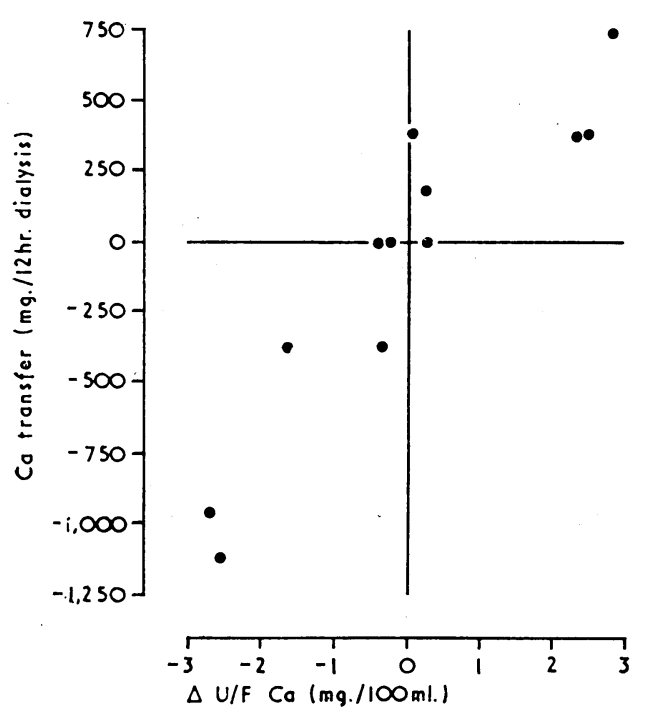

FIG. 5.-Relation between the gradient for ultrafilterable calcium at the beginning of dialysis and the measured external measured external calcium balance. The gradient has been calculated by subtracting the total plasma tion of the dialysis fluid used.

Pendras and Erickson (1966) described a form of metabolic bone disease which they observed in several of the patients treated in Seattle. It was characterized by a gradual increase in plasma alkaline phosphatase levels and radiological appearances of demineralization. After several years' dialysis pathological fractures occurred in some patients. These workers were using a calcium concentration of only $5 \mathrm{mg} . / 100 \mathrm{ml}$. in their dialysis fluid. A fall in alkaline phosphatase levels occurred when vitamin $\mathrm{D}$ was given in large doses (Pendras and Erickson, 1966). However, one of these patients who was treated with vitamin $\mathrm{D}$ recently died with myocardial and pulmonary calcinosis (Davidson and Pendras, 1967). A similar progressive rise in alkaline phosphatase has been observed in one patient treated at Fulham (Figs. 3 and 4). The trend was arrested when the calcium concentration was increased from 5 to $6 \mathrm{mg}$. $/ 100 \mathrm{ml}$.

In order to avoid a negative dialysis calcium balance in a patient with a total plasma calcium level at the upper limit of the normal range-that is, $10.6 \mathrm{mg} . / 100 \mathrm{ml}$.-who will be predicted to have an ultrafilterable calcium of $6 \mathrm{mg} . / 100 \mathrm{ml}$.that is, $10.6 \times 0.56 \mathrm{mg}$. $/ 100 \mathrm{ml}$.- a dialysis fluid calcium concentration of $6 \mathrm{mg} . / 100 \mathrm{ml}$. is required. A minimum concentration of $5.8 \mathrm{mg} . / 100 \mathrm{ml}$. will prevent a negative balance in all patients whose plasma calcium does not exceed $10.3 \mathrm{mg}$./ $100 \mathrm{ml}$. In most patients this level will result in a positive dialysis calcium balance, but in view of the high intestinal losses this may be advantageous. It is important to avoid a continued stimulus to parathyroid secretion in patients whose hypercalcaemia may reflect a process of involution of hyperparathyroidism (Wing et al., 1968).

It is widely held that the maximum level for the calcium concentration of the dialysis fluid is dictated by the risks of metastatic calcification (Shaldon, 1966 ; Sokol et al., 1967). In the patients treated at Fulham, metastatic calcification has been prevented by adequate dialysis and by not permitting the calcium $\times$ phosphate product to rise above 75 . The product is best controlled by lowering the plasma phosphate. This has been achieved by administering aluminium hydroxide to bind phosphate in the gut (Lindholm, 1962).

There has been a tendency for plasma phosphate to fall progressively over the years in these patients, and aluminium hydroxide is rarely required to keep the product below 75 . It is thought that this is the result of a combination of three mechanisms. Firstly, the removal of phosphate by dialysis will nccur only if dialysis of sufficient length and efficiency is per- formed because of the poor dialysance of phosphate (Maher et al., 1965). Secondly, plasma phosphate will fall as involution of any pre-existent hyperparathyroidism occurs, since the effect of parathyroid hormone on extrarenal tissues is such as to raise the plasma phosphate (Stanbury et al., 1960 ; Pechet et al., 1967). Thirdly, the lowering of the plasma phosphate will occur if the large quantity of unmineralized osteoid present in the skeletons of some of these patients (Garner and Ball, 1966) becomes capable of acting as a nucleating site for the deposition of calcium phosphate. This will occur when ultrafilterable inhibitors of calcification (Yendt et al., 1955) are removed by dialysis. Deposition of calcium phosphate can occur only if there is sufficient calcium available.

The maximum level for the calcium concentration of the dialysis fluid is therefore the highest which does not cause complications due to the transient hypercalcaemia which it produces. During the period in which a concentration of $6.5 \mathrm{mg} . / 100 \mathrm{ml}$. was used for several months it was noticed that occasional patients experienced nausea and vomiting during dialysis. Provided that the plasma calcium level at the end of dialysis did not exceed $12 \mathrm{mg} . / 100 \mathrm{ml}$. in any of these patients these symptoms did not occur. However, a rise in plasma calcium of only $2 \mathrm{mg}$./100 ml. has been shown to increase the gastric acidity (Barreras and Donaldson, 1967), and this is probably best avoided. It has been avoided by not exceeding $6.2 \mathrm{mg} . / 100 \mathrm{ml}$. calcium concentration in the dialysis fluid.

Escimations of unfilterable calcium and studies in calcium balance were carried out in Miss E. M. Clarkson's laboratory. Her advice and the technical assistance of $\mathrm{Mr}$. B. McAuliffe are gratefully acknowledged.

\section{REFERENCES}

Barreras, R. F., and Donaldson, R. M. (1967). New Engl. F. Med., 276,

Care, A. D., Sherwood, L. M., Potts, J. T., and Aurbach, G. D. (1966). Nature (Lond.), 209, 55.

Clarkson, E. M., McDonald, S. J. and de Wardener, H. E. (1966). Clin. Sci., 30, 425 .

Curtis, F. K., Davidson, R. C., and Pendras, J. P. (1966). Proceedings of III International Congress on Nephrology, W ashington, Abstracts, p. 176.

Curtis, J. R., Eastwood, J. B., Smith, E. K. M., de Wardener, H. E., and Wing, A. J. (1968). Quart. F. Med., in press.

Davidson, R. C., and Pendras, J. P. (1967). Trans. Amer. Soc. artif. intern. Organs, 13, 20.

Freeman, R. B., Maher, J. F., Schreiner, G. E. (1965). Trans. Amer. Soc. artif. intern. Organs, 11, 99.

Garner, A., and Ball, J. (1966). F. Path. Bact., 91, 545.

Kaye, M., Mangel, R., and Neubauer, E. (1966). Proceedings of European Dialysis and Transplant Association, vol. 3 , p. 17. Excerpta Medica international Congress Series, No. 131. Amsterdam

Kind, P. R. N., and King, E. J. (1954). I. clin. Path., 7, 322.

Lindholm, T. (1962). Acta med. scand., 172, 75 .

Maher, J. F., Freeman, R. B., and Schreiner, G. E. (1965). Ann. intern. Med., $6 \ddot{2}, 535$.

Nordin, B. E. C., and Smith, D. A. (1965). Diagnostic Procedures in Disorders of Calcium Metabolism. London.

Ogden, D. A., and Holmes, J. H. (1966). Trans. Amer. Soc. artif. intern. Organs, 12, 200.

Patel, R., Vertes, V., Bloomfield, D., and Levy, M. (1967). Trans. Amer. Soc. artif. intern. Organs, 13, 5. Pechet, M. M., Bobadilla, E., Carroll, E. L., and Hesse, R. H. (1967).
Amer. F. Med., 43, 696.

Pendras, J. P., and Erickson, R. V. (1966). Ann. intern. Med., 64, 293.

Prasad, A. S., and Flink, E. B. (1958). 7. Lab. clin. Med., 52, 1.

Schreiner, G. E., Maher, J. F., Freeman, R. B., and O'Connell, J. M. B. (1966). In Proceedings of III International Congress on Nephrology, edited by E. L. Becker, vol. 3 , p. 316 . Basle.

Shaldon, S. (1966). Postgrad. med. F., 42, November Suppl.

Sokol, A., Gral, T. Edelabum, D. N.., Rosen, V., and Rubini, M. E. (1967). Trans. Amer. Soc. artif. Örgans, 13, 51.

Stanbury, S. W., Lumb, G. A., and Nicholson, W. F. (1960). Lancet, 1,793

Talmage, R. V., Elliott J. R., and Enders, A. C. (1957). Endocrinology,

Toribara, T. Y., Terepka, A. R., and Dewey, P. A. (1957). F. clin. Invest.,

Trinder, P. (1960). Analyst, 85, 889.

Verberckmoes, R. (1966). Proceedings of European Dialysis and Transplant Association, vol. 3, p. 28, Excerpta Medica International Congress Series No. 131. Amsterdam.

Wing, A. J., Curtis, J. R., Eastwood J. B., Smith, E. K. M., and de Wardener, H. E. (1968). Brit. med. Ұ., 4, 150. Yendt. E. R., Connor, T. B., and Howard, J. E. (1955). Bull. Fohns
Hopk. Hosp., 96, 1. 